\title{
Avaliação laboratorial da doença residual mínima na leucemia mielóide crônica por Real-Time PCR
}

\section{Evaluation diagnosis of minimal residual disease in chronic myeloid leukemia by Real-Time PCR}

Allyne Cristina Grando'; Sandrine Comparsi Wagner²

unitermos

Leucemia mielóide crônica

Doença residual mínima

Real-time PCR

\section{resumo}

A leucemia mielóide crônica (LMC) representa 15\% das leucemias e apresenta três fases: crônica, acelerada e crise blástica. A partir da análise citogenética, pode ser identificado o cromossomo Philadelphia, característico da LMC. O transplante de células-tronco é o único tratamento curativo, mas é acompanhado de altas taxas de morbimortalidade, dificultando sua aplicação. A doença residual mínima é de grande importância para avaliar a resposta ao tratamento, tanto na verificação de doença residual, quanto na identificação de pacientes com alto risco de recaída. Muitas técnicas específicas têm sido introduzidas para detectar as translocações ou os produtos do cromossomo Philadelphia. A mais sensível é a Real-Time PCR, que detecta uma célula leucêmica em $10^{5}$ células normais. $O$ objetivo deste trabalho foi realizar uma revisão bibliográfica sobre a LMC, dando ênfase à utilização da técnica por Real-Time PCR.

\section{abstract}

Chronic myeloid leukemia (CML) represents about 15\% of all leukemias and has three phases: the chronic phase, accelerated phase and blast crisis. After cytogenetic analysis, the Philadelphia chromosome, characteristic of CML, can be identificated. Stem cell transplantation is the only curative treatment for CML, but it is accompanied by high levels of morbimortality, difficulting its application. The minimal residual disease is very important for the evaluation of the response to treatment, to verify the residual disease and also to identify patients with a high risk of relapse. Many specific techniques have been introduced for the detection of translocations or products of the Philadelphia chromosome; the most sensitive being Real-Time $P C R$ which detects 1 leukemia cell in $10^{5}$ normal cells. The aim of this study was to perform a bibliographic review of CML, with emphasis on the utilization of the Real-Time PCR technique. key words

Chronic myeloid leukemia

Minimal residual disease

Real-Time PCR 


\section{Introdução}

A leucemia mielóide crônica (LMC) é uma desordem clonal maligna de células-tronco hematopoiéticas ${ }^{(6,24,71)}$, que resulta no aumento de células mielóides, eritróides e plaquetas no sangue periférico, além de acentuada hiperplasia mielóide na medula óssea ${ }^{(3,63)}$. Foi denominada pela primeira vez, em 1847, como uma "leucemia esplênica" e, após 30 anos, foi definida como uma "leucemia mielóide"(44). Somente na primeira metade do século 19 foi reconhecida como uma forma distinta de leucemia ${ }^{(33)}$.

O curso natural da LMC é, geralmente, caracterizado por três fases seqüenciais, denominadas como crônica, acelerada e crise blástica ${ }^{(15,47,71)}$. A maioria dos pacientes é diagnosticada na fase crônica ${ }^{(13)}$, que é caracterizada por uma grande proliferação clonal das células sangüíneas ${ }^{(13,57)}$. Sem tratamento, a progressão da doença é inevitável(8), e os pacientes entram na fase blástica. A maioria dos casos é precedida pela fase acelerada, com achados laboratoriais e clínicos bem definidos ${ }^{(13,16,20,48,55,57)}$. A progressão do início da fase crônica até a crise blástica ocorre dentro de três a cinco anos ${ }^{(20,57,63)}$.

A LMC representa cerca de $15 \%$ do total das leucemias, acometendo em torno de um a dois casos para cada 100 mil indivíduos anualmente ${ }^{(20,50)}$. A doença está presente em ambos os sexos, com freqüência de quatro homens para cada mulher ${ }^{(31)}$. Apresenta um pico de incidência entre 45 e 55 anos ${ }^{(20,50)}$, com uma média de 53 anos ${ }^{(63)}$, podendo acometer em $10 \%$ dos casos pacientes entre 5 e 20 anos ${ }^{(13)}$, e entre 10 e $15 \%$ dos casos em pacientes a partir dos 60 anos ${ }^{(50)}$.

O prognóstico na LMC é variável dependendo da fase da doença, idade e resposta à terapia ${ }^{(66)}$. Em $40 \%$ dos casos é assintomática ${ }^{(63)}$, mas nos pacientes sintomáticos, os achados mais comuns são: fadiga, perda de peso, hemorragia e desconforto abdominal. No exame físico, é possível observar, entre outros achados, púrpuras e esplenomegalia ${ }^{(13,20)}$.

Os achados laboratoriais mais freqüentes são: leucocitose, sendo usualmente maior que $50 \times 10^{9} / \mathrm{l}$ e, algumas vezes, maior que $500 \times 10^{9} / /$, eosinofilia, basofilia, anemia normocrômica e normocítica e trombocitose ${ }^{(20)}$. A medula óssea apresenta-se hipercelular, com predomínio da linhagem granulopoética. A fosfatase alcalina dos neutrófilos pode estar muito diminuída, sendo um exame rápido para a triagem dessa patologia. É possível encontrar um aumento da vitamina $B$ sérica e na capacidade de ligação de vitamina $B_{12}$ além de uma hiperuricemia. $A$ presença do cromossomo Philadelphia na análise citogenética do sangue periférico e da medula óssea define a condição diagnóstica ${ }^{(31)}$.

\section{Cromossomo Philadelphia}

Com os avanços da citogenética, no ano de 1960 foi descoberto o cromossomo Philadelphia $(\mathrm{Ph})^{(4,13,14,33,66)}$, e treze anos após foi descrita a translocação recíproca $t(9 ; 22)$ (q34; q11) entre os braços longos dos cromossomos 9 e $22^{(4,17,20,23,25,34,39,44,70)}$. O cromossomo Ph está presente entre 90 e $95 \%$ dos pacientes com $\operatorname{LMC}(3,6,17,22,24,59)$, mas também é encontrado em $5 \%$ das crianças e em 15\% a $30 \%$ dos adultos com leucemia linfóide aguda (LLA), e em $2 \%$ dos pacientes com diagnóstico inicial de leucemia mieloblástica aguda $(\mathrm{LMA})^{(3,20)}$. Os outros $5 \%$ a $10 \%$ dos pacientes $\mathrm{Ph}$ negativos possuem complexas translocações variantes que resultam na mesma alteração ${ }^{(27,63)}$.

$\mathrm{O}$ cromossomo $\mathrm{Ph}$ resulta da fusão do gene BCR (breakpoint cluster region) no cromossomo 22q11 com o gene $\mathrm{ABL}$ (abelson leukemia virus), localizado no cromossomo $9 q 34^{(3,13,50)}$. O ponto de quebra no gene BCR está localizado em uma região $5.8 \mathrm{~kb}$, chamada major breakpoint cluster region $\mathrm{M}-\mathrm{bcr}$, que possui 5 éxons (b1 a b5), correspondendo aos éxons 12 a 16 do gene BCR. Geralmente, a quebra do M-bcr ocorre dentro de íntrons localizados entre os éxons b2 (e13) e b3 (e14) ou éxons b3 (e14) e b4 (e15), que se liga ao éxon a2 do $A B L$, formando os genes quiméricos $B 2 A 2$ ou $B 3 A 2$, sendo 75 pares de bases diferentes um do outro. Enquanto a parte $5^{\prime}$ do BCR permanece no cromossomo $\mathrm{Ph}$, formando a seqüência $5^{\prime}$ do novo gene híbrido, a seqüência do BCR localizada a $3^{\prime}$ do ponto de quebra transloca para o cromossomo $9 q+$, originando um gene híbrido $B C R / A B L^{(3)}$ que é transcrito como um quimérico $B C R-A B L$ de RNA mensageiro (mRNA) ${ }^{(20,34,59)}$. O oncogene híbrido bcr/abl resultante desta aposição promove a síntese de uma oncoproteína com atividade tirosinocinase, responsável por estímulos à proliferação e ao bloqueio na apoptose da célula progenitora hematopoiética ${ }^{(11,14,23,24,32,34,39,50)}$. Esta alteração molecular é a responsável pelo desenvolvimento da $\mathrm{LMC}^{(24)}$.

Durante a evolução da fase blástica podem ocorrer mutações secundárias e mudanças citogenéticas, como a trissomia e isocromossomia $17^{(13)}$, duplicação do cromossomo Ph e trissomia do cromossomo 8. Mutações ou deleções de genes supressores de tumores como $p 16$ e $p 53$ podem ocorrer com uma freqüência variável e contribuem para o fenótipo maligno ${ }^{(57,63)}$. 


\section{Tratamento}

O arsenal terapêutico da LMC está compreendido na escolha racional entre a terapia celular, através do transplante de células-tronco hematopoiética (TCTH), e o tratamento medicamentoso ${ }^{(50)}$.

No início de 1980, o TCTH foi o primeiro tratamento usado em pacientes com LMC na fase crônica e é considerado como único tratamento capaz de promover a cura. Muitos pacientes sobrevivem por longos períodos após o transplante sem evidência de recaída, sendo considerados como "curados", embora o mecanismo de entendimento deste processo não seja bem definido. A taxa de cura oscila em torno de $65 \%$, podendo atingir uma sobrevida de $70 \%$ em dez anos. Entretanto, essas taxas podem variar, dependendo da idade, da compatibilidade com o doador, da combinação de sexo, do tempo entre o diagnóstico e o transplante e da fase da doença em que se encontra. Apesar do seu poder de cura, somente $15 \%$ a $30 \%$ dos pacientes serão candidatos a este procedimento, tendo como principais limitantes a idade e a indisponibilidade de doador compatível. Além disso, as taxas de recidiva após o TCTH variam de $5 \%$ a $30 \%$ na fase crônica, $60 \%$ na fase acelerada e $90 \%$ na fase blástica ${ }^{(9,13,21,25,28,37,50,57,58,63,66)}$.

Os pacientes com recidiva após o TCTH vêm sendo tratados, nos últimos anos, com o uso de interferon alfa, quimioterapia ou um segundo TCTH. No entanto, a infusão de linfócitos do doador (DLI - donor lymphocytes infusion), através da reação enxerto contra leucemia, tem se constituído o tratamento de primeira linha. Uma resposta molecular completa tem sido alcançada em até $70 \%$ dos pacientes em fase crônica com tal recurso terapêutico. Apesar de sua alta capacidade de resposta molecular, o uso da DLI traz as complicações da mielossupressão e a considerável morbimortalidade da doença do enxerto contra hospedeiro (DECH), presente em mais de $60 \%$ desta população, o que tem limitado sua aplicação em um número considerável de pacientes $^{(50)}$.

Entre os tratamentos medicamentosos, encontram-se a hidroxiuréia, o busulfan, o interferon alfa e os inibidores da tirosinocinase. A hidroxiuréia é preferida ao busulfan porque a média de duração da fase crônica e a média de sobrevivência são, significativamente, melhores em uma comparação a longo tempo de terapia. A hidroxiuréia é vantajosa pelo seu perfil de alta toxicidade nas células leucêmicas. Entre os efeitos colaterais da hidroxiuréia estão: citopenias, náuseas e erupções na pele. O busulfan, além desses efeitos colaterais, também pode provocar aplasia de medula óssea ${ }^{(63)}$.
O mecanismo de ação do interferon alfa nas células leucêmicas ainda não é bem conhecido, mas acredita-se que ele exerça uma influência indireta na sobrevida dessas células ${ }^{(20,63)}$. Ele é capaz de induzir remissões hematológicas e citogenéticas completas ou parciais em pacientes com LMC na fase crônica ${ }^{(2,30)}$. Uma resposta citogenética completa, que é definida pela ausência de célula Ph positivas, e uma resposta citogenética parcial maior, que é definida pela presença de $1 \%$ a $35 \%$ de células $\mathrm{Ph}$ positivas em metáfase, ocorrem entre $20 \%$ e $30 \%$ dos pacientes. Uma resposta citogenética parcial menor, que é definida pela presença de $36 \%$ a $65 \%$ de células Ph positivas em metáfase, ocorre em mais $10 \%$ dos pacientes. Há também a resposta citogenética parcial mínima, que é definida pela presença de $66 \%$ a $95 \%$ de células Ph positivas em metáfase e ocorre no restante dos pacientes ${ }^{(16,63)}$. Entre os efeitos colaterais do interferon alfa estão: febre, erupções na pele, mialgias, depressão e trombocitopenia(63).

Em 1998, ocorreu a introdução da primeira classe de inibidores da tirosinocinase, o mesilato de imatinibe (MI) (STI-571, Gleevec ${ }^{\circledR}$ ), que demonstrou ser um marco divisório no controle da $\operatorname{LMC}^{(25,34,50,51)}$. A droga reduz substancialmente a quantidade de células leucêmicas na fase crônica da doença e prolonga a sobrevida em comparação com agentes convencionais ${ }^{(13,25,38)}$. Em dezembro de 2002, o Ml foi aprovado como a primeira linha de tratamento para diagnósticos recentes em pacientes com $\operatorname{LMC}^{(11,13,26,35,71)}$, sendo capaz de

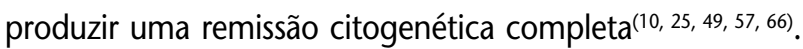
Porém, se houver a interrupção do tratamento, os pacientes podem recidivar e, como conseqüência, progredir até a fase terminal da doença(49, 57$)$.

O Ml age como um inibidor específico da proteína com atividade tirosinocinase, produzida pelo gene bcr/abl, impedindo a fosforilação de substratos envolvidos na regulação do ciclo celular ${ }^{(2,14,23,34,45,50,67,71,73)}$. Em humanos, o Ml induz uma rápida e completa resposta hematológica em quase todos os pacientes com LMC Cromossomo Ph positivo na fase crônica, em $50 \%$ daqueles pacientes na fase acelerada e, ainda, em uma pequena proporção daqueles pacientes que estão na fase blástica ${ }^{(9,62)}$ ou aqueles com Leucemia Aguda Cromossomo $\mathrm{Ph}$ positivo ${ }^{(63)}$.

$\mathrm{O} \mathrm{Ml}$ é bem tolerado pela maioria dos pacientes. Os efeitos colaterais mais comuns incluem edema, diarréia, náusea, cãibra muscular, dor muscular e óssea, além de erupções cutâneas. Os efeitos menos comuns incluem fadiga, dor de cabeça, prurido, toxicidade hepática e mielossupressão(13).

Apesar da eficácia e da segurança do tratamento com MI, recaída e resistência podem ocorrer em alguns pacien- 
tes, particularmente naqueles em fase acelerada ou em crise blástica. A recaída ocorre em quase todos os pacientes tratados na fase blástica, enquanto aproximadamente 15\% a $20 \%$ dos pacientes na fase crônica apresentam recaídas após os primeiros 2-3 anos de terapia. A maioria dos pacientes que adquire resistência após uma resposta inicial tem evidenciado a ativação da tirosinocinase BCR-ABL que ocorre devido a mutações. Acredita-se que as mutações surgem da pressão seletiva da terapia com Ml, e essas mutações podem variar no seu nível de resistência ${ }^{(5)}$.

\section{Doença residual mínima}

A doença residual mínima (DRM) é definida como um pequeno número de células leucêmicas, que não podem ser detectadas por morfologia ou análise citogenética ${ }^{(6)}$. Possui valor prognóstico considerável em muitas malignidades hematológicas, incluindo LLA, LMA, linfomas, mieloma múltiplo e $\operatorname{LMC}(22,55,69)$, já que, atingida a remissão hematológica completa, uma grande proporção de células leucêmicas permanece em níveis abaixo do limite de detecção do microscópio ótico ${ }^{(42)}$.

O grau de redução da carga tumoral é expressa em três níveis: (1) resposta hematológica, definida como a normalização do hemograma e o desaparecimento da esplenomegalia; (2) resposta citogenética, definida como a proporção de metáfases residuais $\mathrm{Ph}$ positivas; e (3) resposta molecular, definida como a proporção de resíduos do gene BCR-ABL, da proteína ou do transcrito ${ }^{(30,64)}$.

A identificação da DRM tem por objetivo entender o significado biológico e clínico da leucemia que persiste nos pacientes com remissão completa patológica ${ }^{(7,55)}$. O foco da DRM é redefinir o conceito da remissão usando técnicas moleculares mais sensíveis, que detectem níveis da doença abaixo da patologia convencional(56). A DRM está envolvida na identificação de pacientes com alto risco de recaída para explicar como a leucemia pode recidivar em pacientes tidos como "curados"(55).

A detecção e o monitoramento da DRM têm-se tornado o tópico mais prevalente na terapia da $\operatorname{LMC}^{(19,41)}$. As informações específicas habilitam uma intervenção precoce no tratamento. Baseado nisso, a detecção da DRM vem sendo adotada como rotina em protocolos de tratamento, sendo muito usada para guiar a terapia ou para a avaliação de novas modalidades de tratamento $(7,12,25,41,69)$.

Muitas técnicas têm sido introduzidas com especificidade para detectar as translocações ou os produtos do cromossomo Ph. Essas técnicas incluem hibridização de fluorescência in situ (FISH), Southern blotting, reação em cadeia da polimerase transcriptase reversa (RT-PCR) qualitativa e reação em cadeia da polimerase transcriptase reversa - Real Time quantitativa (RQ-PCR) ${ }^{(29,72)}$.

\section{Diagnóstico laboratorial por Real-Time PCR}

A RT-PCR qualitativa, que avalia a presença ou ausência dos transcritos BCR-ABL, foi introduzida no final de 1980, mas logo foi superada em 1992 por uma PCR quantitativa (RQ-PCR) que garante informações muito mais precisas sobre o nível da DRM ${ }^{(17,32,33,37,41)}$. A partir do final da década de 90, a técnica RQ-PCR foi implantada para estudos da DRM em pacientes tratados com malignidades hematológicas ${ }^{(22,41)} \mathrm{e}$, em especial, no acompanhamento

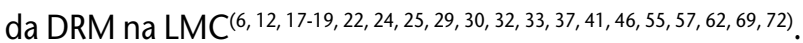
O método mede, em cada amostra, o número de cópias de $m R N A$ produzido pela proteína $p 210$ do gene $B C R / A B L^{(59)}$. O método da RQ-PCR é de execução rápida ${ }^{(46)}$ e apresenta boa reprodutibilidade ${ }^{(18,19)}$.

A RQ-PCR permite uma quantificação precisa dos produtos de PCR durante a fase exponencial da amplificação, em contraste com a PCR clássica e a sua quantificação de ponto final(22). É baseada no uso de sondas fluorescentes com seqüências específicas, que hibridizam com a seqüência alvo, emitindo um sinal fluorescente. $\mathrm{O}$ sistema permite correlacionar a intensidade do sinal com a quantidade do produto amplificado; com isto, há um aumento de precisão e exatidão. Além disso, a quantificação pode ser obtida em um pequeno período de tempo e o processo pós-PCR não é necessário, reduzindo drasticamente o risco de contaminação e evitando o contato com as substâncias químicas da PCR, tais como o brometo de etídio ou os marcadores radioativos $(22,30,36,74)$.

Entre as principais tecnologias da PCR em tempo real, estão os dois sistemas mais usados, conhecidos como SYBR Green e TaqMan ${ }^{(1,36)}$. O SYBR Green é um corante que se liga na fita dupla de DNA. Durante os ciclos consecutivos da PCR, a quantidade de DNA de fita dupla se eleva de maneira exponencial, aumentando, assim, a quantidade de SYBR Green ligado e, conseqüentemente, a fluorescência emitida. Porém, ocorrendo amplificações inespecíficas, estas são detectadas, interferindo na quantificação final dos produtos específicos da reação. Para avaliar a presença de produtos inespecíficos, uma curva de fusão é construída. Se apenas os produtos específicos foram amplificados, um único pico será visualizado no gráfico de fusão. Entre as vantagens de sua utilização estão o fácil manuseio e o baixo custo. 
A metodologia TaqMan utiliza a atividade exonucleásica 5'-3' da Taq $^{\circledast}$ DNA polimerase e tem sido amplamente utilizada. Essa enzima digere uma sonda marcada, que anela especificamente na parte interna do seguimento a ser amplificado entre dois primers. A sonda TaqMan possui na extremidade $5^{\prime}$ uma molécula fluorescente e na extremidade 3' outra molécula, que pode ser ou não ser fluorescente, de comprimento de onda diferente. Enquanto a reação de PCR se processa, a polimerase sintetiza novas cadeias a partir dos primers e cliva a sonda correspondente, resultando em aumento do sinal fluorescente, que é captado a cada ciclo até atingir um limiar, no qual todas as amostras podem ser comparadas ${ }^{(1)}$.

Os resultados da RQ-PCR são expressos na forma de razão entre a amplificação de um gene de interesse e um controle endógeno ${ }^{(36)}$. Geralmente, na monitoração da DRM os genes ABL ou G6PD (glicose 6-fosfato-desidrogenase) são usados como controles endógenos na quantificação do $B C R / A B L$. Os resultados são expressos na forma de razões $B C R-A B L / A B L$ ou BCR-ABL/G6PD(29). A expressão dos resultados em razões $B C R-A B L / A B L$ elimina a interferência de variáveis na qualidade do RNA, na sua quantificação e na eficiência da transcrição reversa ${ }^{(1)}$. Como controle positivo e teste de sensibilidade e reprodutibilidade, são usadas diluições seriadas de concentração, conhecidas de células da linhagem K562 BCR/ABL positivas, em que se inicia a detecção com 10 cópias do DNA de BCR/ABL em água ${ }^{(6,46)}$.

Um dos primeiros estudos foi realizado por Lion et al, em 1992, relatando dois casos clínicos de pacientes com LMC cromossomo Ph positivo, com monitoração por RQ-PCR, sendo destacada a importância da monitoração da DRM por RQ-PCR pela sua potencialidade em detectar clones neoplásicos que expressam o mRNA quimérico de $B C R / A B L$ no sangue periférico e na medula óssea no decorrer do tratamento(41).

Em 1999, foi realizado um estudo retrospectivo em 13 pacientes com LMC, 10 após TCTH alogênico e três após TCTH autólogo, que haviam sido monitorados por RT-PCR e RQ-PCR. Após o TCTH, sete pacientes apresentaram resultados negativos para a presença de BCR/ABL por RT-PCR e, por RQ-PCR, seis foram negativos. Apesar do pequeno número de amostras avaliadas, a RQ-PCR mostrou-se mais sensível(17).

Um estudo de Schock et al. ${ }^{(64)}$ comparou a técnica de hibridização in situ fluorescente (FISH) com RT-PCR e RQ-PCR em 350 pacientes, e foi concluído que a RQ-PCR é a técnica mais sensível, e também que somente FISH possivelmente não é uma técnica suficiente para o monitoramento da $\mathrm{DRM}^{(64)}$. No mesmo ano, Kaeda et al, apresentaram resultados das análises de 216 amostras negativas para RT-PCR. Destas, $51,9 \%$ foram positivas para RQ-PCR, enquanto apenas $6,3 \%$ das amostras negativas para RQ-PCR foram positivas para RT-PCR, sugerindo, também, que a RQ-PCR é a técnica mais sensível(37).

Em outro estudo, Gabert et al. ${ }^{(22)}$, envolvendo 26 laboratórios de 10 países da Europa, criaram e aplicaram um protocolo para unificar a técnica para RQ-PCR com 278 amostras. $\mathrm{O}$ estudo deteve-se na fusão gênica do cromossomo $\mathrm{Ph}$, sendo que quatro fases do programa foram seguidas: (1) treinamento da equipe; (2) adaptação da técnica; (3) teste de sensibilidade; e (4) amostras de pacientes para teste. O estudo concluiu a importância do desenvolvimento do protocolo para a técnica de RQ-PCR para análise da fusão gênica do Ph para a determinação da DRM para uma possível intervenção precoce do tratamento ${ }^{(22)}$. Logo após, num estudo em 2004, que aplicou o protocolo estabelecido, foi determinada a remissão citogenética e resposta molecular por RQ-PCR de 191 pacientes Cromossomo Ph positivos na fase crônica tratados com Ml e previamente tratados com interferon alfa. Uma completa remissão citogenética foi obtida em 85 pacientes e manteve-se por dois anos em 67 destes. Após 36 meses, os transcritos foram indetectáveis em 22 pacientes e apenas um destes recaiu ${ }^{(62)}$.

Em 2005, Galimberti et al. compararam amostras de 33 pacientes em remissão pelas técnicas de RT-PCR e RQPCR. A sensibilidade do método quantitativo foi testada em comparação ao método qualitativo e o método quantitativo mostrou uma sensibilidade significantemente maior ${ }^{(24)}$.

Em 2006, Hughes relatou em seu estudo que a técnica da RQ-PCR permite uma medida precisa do total de células leucêmicas e do grau no qual os transcritos $B C R / A B L$ são reduzidos pela terapia, correlacionando com a progressão de sobrevida ${ }^{(33)}$.

Em um estudo de Lemos et al. ${ }^{(40)}$, foram acompanhados 22 pacientes com LMC durante o tratamento com MI, sendo que $68 \%$ da fase crônica, $23 \%$ da fase acelerada e $9 \%$ da crise blástica. As coletas de sangue periférico e medula óssea foram realizadas no dia zero do tratamento, 3 meses e 6 meses após o início. A expressão de BCR/ABL no terceiro mês obteve um discreto aumento em relação ao dia zero, mas ocorreu um significativo decréscimo após o sexto mês. Mais de $73 \%$ dos pacientes obtiveram um decréscimo de $80 \%$ da expressão de $B C R / A B L$, e apenas $27 \%$ dos pacientes obtiveram aumento dos transcritos. Nesses $27 \%$, especula-se que tenham ocorrido mutações 
na tirosinocinase $\mathrm{BCR} / \mathrm{ABL}$ associadas à resistência ao $\mathrm{Ml}$. Foram realizadas análises entre os transcritos $B 2 A 2$ e B3A2, sendo encontrada uma diferença estatisticamente significativa entre os níveis de expressão dos transcritos B2A2 e B3A2 após o sexto mês, onde a redução dos níveis de $B C R / A B L$ ocorreu preferencialmente nos pacientes com os transcritos $B 2 A 2^{(40)}$.

Os diferentes transcritos de BCR/ABL estão submetidos a investigações na sua função como fator de prognóstico na sobrevida e sua correlação com os aspectos clínicos da $\mathrm{LMC}^{(40)}$. Alguns pesquisadores apontam funções ainda controversas ${ }^{(60)}$, e outros acreditam que diferentes transcritos não possuem valor prognóstico ou correlação com características clínicas ${ }^{(53,68)}$. Entretanto, parece claro que o transcrito B3A2 está associado com um aumento da contagem de plaquetas, o que pode indicar uma influência deste transcrito na trombocitopoiese ${ }^{(43,52,65)}$, apesar de faltar uma correlação com o prognóstico(68).

\section{Discussão e conclusão}

Desde a introdução, na segunda metade dos anos 1990, a técnica da RQ-PCR tem sido rapidamente implantada para os estudos da DRM em pacientes tratados com malignidades hematológicas. A avaliação da DRM por RQ-PCR marca a possibilidade de detectar a recaída em muitos pacientes, promovendo a possibilidade de uma nova modalidade de tratamento ${ }^{(64)}$. A sensibilidade do método RQ-PCR, segundo Mensink em 1998, é a detecção de uma célula leucêmica em $10^{5}$ células normais. Porém, em 1999, um estudo de Branford mostrou a detecção de uma célula leucêmica em
$10^{5}$ ou $10^{6}$ células normais. Esse número foi confirmado em um estudo posterior, em 2005, por Goldman $(6,13,25,46)$. Atualmente, essa sensibilidade é considerada, aproximadamente, mil vezes maior do que o limite de detecção dos outros métodos ${ }^{(12)}$.

A quantificação dos transcritos de BCR/ABL permite um acompanhamento adequado da evolução e eficácia do tratamento, permitindo monitorar mudanças que possam levar a uma possível recidiva da doença. A RQ-PCR demonstra ser a tecnologia de escolha para esta finalidade, uma vez que fornece resultados quantitativos de maneira legítima e permite avaliar a evolução dos transcritos de BCR/ABL durante o curso da doença $a^{(1)}$.

A RQ-PCR é rápida, precisa, exata e sensível para a quantificação do $B C R / A B L$ no sangue periférico ${ }^{(6,54,61)}$. O ensaio é considerado de alta reprodutibilidade, combinado com a sensibilidade, precisão e ampla dinâmica e, ainda, confiável alcance de quantificação. É o método preferido para monitoração da DRM e tratamento da resposta a terapia em pacientes com $\operatorname{LMC}(6,18,19,29,54,61)$.

A RQ-PCR tem como vantagem ser facilmente padronizada, e em breve deverá ser implantada na rotina clínica, não apenas no acompanhamento do tratamento da LMC, mas também nas demais leucemias que apresentam marcadores moleculares reconhecidos(1).

\section{Agradecimentos}

Agradecemos especialmente à Dra. Laura Fogliatto e à Dra. Nicola Conran, pela colaboração e disponibilidade para a revisão final do artigo.

\section{Referências}

1. ALMEIDA, P. S. R.; SADDI, V. A. Monitoramento de doença residual mínima em leucemia mielóide crônica por PCR em tempo real. Rev Bras Hematol Hemoter, v. 29, v. 4, p. 382-6, 2007.

2. BACCARANI, M. et al. Envolving concepts management of chronic myeloid leukemia: recommendations from an expert panel on behalf of the European LeukemiaNet. Blood, v. 108, n. 6, p. 1809-20, 2006.

3. BARBOZA, L. et al. Análise de transcritos da translocação t $(9 ; 22)$ em leucemia mielóide crônica. Rev Bras Hematol Hemoter, v. 22, n. 2, p. 89-98, 2000.

4. BENCH, A. J.; ERBER, W. N.; SCOTT, M. A. Molecular genetic analysis of haematological malignancies: I. Acute leukaemias and myeloproliferative disorders. Clin Lab Haematol, v. 27, p. 148-71, 2005.
5. BRANFORD, S.; HUGHES, T. Detection of BCR-ABL mutations and resistance to imatinib mesylate. Methods Mol Med, v. 125, p. 93-106, 2006.

6. BRANFORD, S.; HUGHES, T. P.; RUDZKI, Z. Monitoring chronic myeloid leukaemia therapy by real-time quantitative PCR in blood is a reliable alternative to bone marrow cytogenetics. Br J Haematol, v. 107, p. 587-99, 1999.

7. CHUNG, N. G.; BUXHOFER-AUSCH, V.; RADICH, J. P. The detection and significance of minimal residual disease in acute and chronic leukemia. J Compilation, v. 68, p. 371-85, 2006

8. CORTES, J. Natural history and significance of chronic myelogenous leukemia. Hematol Oncol Clin North Am, v. 18, n. 3, p. 569-84, 2004. 
9. CORTES, J. et al. Dasatinib induces complete hematologic and cytogenetic responses in patients with imatinibresistant or -intolerant chronic myeloid leukemia in blast crisis. Blood, v. 109, n. 8, p. 3207-13, 2007.

10. CORTES, J.; O'DWYER, M. E. Clonal evolution in chronic myelogenous leukemia. Hematol Oncol Clin North Am, v. 18, n. 3, p.671-84, 2004.

11. COWAY-JACOB, S. W. et al. Structural biology contributions to the discovery of drugs to treat chronic myelogenous leukaemia. Acta Crystallog D Biol Crystallogr, v. 63, n. 1, p. 80-93, 2007.

12. CROSS, J. Minimal residual disease in chronic myeloid leukaemia. Hematol Cell Ther, v. 40, n. 5, p. 224-8, 1998.

13. D'ANTONIO, J. Chronic myelogenous leukemia. Clin J Oncol Nurs, v. 9, n. 5, p. 535-8, 2005.

14. DRUKER, B. J. et al. Chronic myelogenous leukemia. Hematology, p. 111-35, 2002.

15. DRUKER, B. J. et al. Chronic myelogenous leukemia. Hematology, p. 87-112, 2001.

16. DRUKER, B. J. et al. Efficacy and safety of a specific inhibitor of the BCR-ABL tyrosine kinase in chronic myeloid leukemia. N Engl J Med, v. 344, n. 14, p. 1031-7, 2001.

17. EDER, M. et al. Monitoring of BCR-ABL expression using real-time RT-PCR in 18. CML after bone marrow or peripheral blood stem cell transplantation. Leukemia, v. 13, p. 1383-9, 1999.

18. ELMAAGACLI, A. H. Real-time PCR for monitoring minimal residual disease and chimerism in patients after allogenic transplantation. Int J Hematol, v. 76, n. 2, p. 204-5, 2002.

19. FADERL, S.; HOCHHAUS, A.; HUGHES, T. Monitoring of minimal residual disease in chronic myeloid leukemia. Hematol Oncol Clin North Am, v. 18, n. 3, p. 657-70, 2004.

20. FADERL, S. et al. The biology of chronic myeloid leukemia. N Engl J Med, v. 341, n. 3, p. 164-72, 1999.

21. FRUEHAUF, S. et al. Imatinib combined with mitoxantrone/ etoposide and cytarabine is an effective induction therapy for patients with chronic myeloid leukemia in myeloid blast crisis. Blood, v. 109, n. 8, p. 1543-9, 2007.

22. GABERT, J. et al. Standardization and quality control studies of "real-time" quantitative reverse transcriptase polymerase chain reaction of fusion gene transcripts for residual disease detection in leukemia: A Europe Against Cancer Program. Leukemia, v. 17, p. 231857, 2003

23. GADZICKI, D. et al. BCR-ABL gene amplification and overexpression in a patient with chronic myeloid leukemia treated with imatinib. Cancer Genet Cytogenet, v. 159, p. 164-7, 2005.

24. GALIMBERTI, S. et al. Quantitative molecular monitoring of BCR-ABL and MDR1 transcripts in patients with chronic myeloid leukemia during Imatinib treatment. Cancer Genet Cytogenet, v. 162, n. 1, p. 57-62, 2005.

25. GOLDMAN, J. Monitoring minimal residual disease in BCRABL-positive chronic myeloid leukemia in the imatinibe era. Curr Opin Hematol, v. 12, p. 33-9,2005.

26. GORDON, M. K. et al. Successful autologous stem cell collection in patients with chronic myeloid leukemia in complete cytogenetic response, with quantitative measurement of BCR-ABL expression in blood, marrow, and apheresis products. Leuk Lymphoma, v. 49, n. 3, p. 531-7, 2008.

27. GORUSU, M. et al. On the genesis and prognosis of variant translocations in chronic myeloid leukemia. Cancer Genet Cytogenet, v. 173, n. 2, p. 97-106, 2007.

28. HEHLMANN, R. et al. Drug treatment is superior to allografting as first line therapy in chronic myeloid leukemia. Blood, v. 109, n. 11, p. 4686-92, 2007.

29. HOCHHAUS, A. Minimal residual disease in chronic myeloid leukaemia patients. Pract Res Clin Haematol, v. 15, n. 1, p. 159-78, 2002.

30. HOCHHAUS, A. et al. Detection and quantification or residual disease in chronic myelogenous leukemia. Leukemia, v. 14, n. 6, p. 998-1005, 2000.

31. HOFfBRAND, A. V.; PETTIT, J. E.; MOSS, P. A. H. Hematologia. 4. ed. São Paulo: Artmed; 2004.

32. HUGHES, T.; BRANFORD, S. Molecular monitoring of $B C R-A B L$ as a guide to clinical management in chronic myeloid leukaemia. Blood Rev, v. 20, n. 1, p. 29-41, 2006.

33. HUGHES, T. et al. Monitoring CML patients responding to treatment with tyrosine kinase inhibitors: review and recommendations for harmonizing current methodology for detecting BCR-ABL transcripts and kinase domain mutations and for expressing results. Blood, v. 108, n. 1, p. 28-37, 2006.

34. JABBOUR, E.; CORTES, J.; KANTARJIAN, H. Novel tyrosine kinase inhibitors in chronic myelogenous leukemia. Curr Opin Hematol, v. 18, p. 578-83, 2006.

35. JABBOUR, E. et al. Targeted therapy in chronic myeloid leukemia. Expert Rev Anticancer Ther, v. 8, n. 1, p. 99-110, 2008.

36. KAEDA, J. et al. Cytogenetic and molecular monitoring of residual disease in chronic myeloid leukaemia. Acta Haematol, v. 107, p. 64-75, 2002.

37. KAEDA, J. et al. Serial measurement of BCR-ABL transcripts in the peripheral blood after allogenic stem cell transplantation for chronic myeloid leukemia: an attempt to define patients who may not require further therapy. Blood, v. 107, n. 10, p. 4171-6, 2006.

38. KANTARJIAN, H. M. et al. Important therapeutic targets in chronic myelogenous leukemia. Clin Cancer Res, v. 13, n. 4, 1089-97, 2007.

39. KURBEGOV, D.; MOLLDREM, J. J. Immunity to chronic myelogenous leukemia. Hematol Oncol Clin North Am, v. 18, p. 733-52, 2004.

40. LEMOS, J. A. R. et al. Differential molecular response of the transcripts B2A2 and B3A2 to imatinib mesylate in chronic myeloid leukemia. Genet Mol Res, v. 4, n. 4, p. 803-11, 2005.

41. LION, T. et al. Monitoring of residual disease in chronic myelogenous leukemia by quantitative polymerase chain reaction. Leukemia, v. 6, n. 6, p. 495-9, 1992.

42. LOWENBERG, B. Minimal residual disease in chronic myeloid leukemia. N Engl J Med, v. 349, n. 15, v. 1399-401, 2003.

43. MELO, V.. J. BCR-ABL genes variants. Baillier's Clin Haematol, v. 10, p. 203-22, 1997. 
44. MELO, V. J. The molecular biology of chronic myeloid leukaemia. Leukemia, v. 10, p. 751-6, 1996.

45. MELO, V. J. Imatinib and ABCG2: who controls whom? Blood, v. 108, n. 4, p. 1116-7, 2006.

46. MENSINK, E. et al. Quantitation of minimal residual disease in Philadelphia chromossome positive chronic myeloid leukaemia patients using real-time quantitative RT-PCR. Br J Haematol, v. 102, p. 768-74, 1998.

47. MICHOR, F. CML blast crisis arises from progenitors. Stem Cells, v. 25, n. 5, p. 1114-8, 2007.

48. MOLLDREM, J. J. et al. Evidence that specific T lymphocytes may participate in the elimination of chronic myelogenous leukemia. Nat Med, v. 6, n. 8, p. 1018-23, 2000.

49. O’BRIEN, S.; TEFFERI, A.; VALENT, P. Chronic nyelogenous leukemia and myeloproliferative disease. Hematology, p.146-62, 2004.

50. PALLOTTA, R. etal. Treatment of chronic myelogenous leukemia relapse after allogenic bone marrow transplantation with imatinib mesylate: Report of three cases. Rev Bras Hematol Hemoter, v. 28, n. 2, p. 157-60, 2006.

51. PELOSINI, M. et al. Skin and stomach graft versus host disease after syngeneic BMT in CML: a case report. Leuk Res, v. 31, n. 11, p. 1603-4, 2007.

52. PEREGO, R. A. et al. The possible influences of B2A2 and B3A2 BCR/ABL protein structure on trombopoiesis in chronic myeloid leukaemia. Eur J Cancer, v. 36, p. 1395-401, 2000.

53. PREJZNER, W. Relationship of the BCR gene breakpoint and the type of BCR/ABL transcript to clinical course, prognostic indexes and survival in patients with chronic myeloid leukemia. Med Sci Monit, v. 8, p. 193-7, 2002.

54. PRESS, R. D. et al. BCR-ABL mRNA levels at and after the time of a complete cytogenetic response (CCR) predict the duration of CCR in imatinibe-treated patients with CML. Blood, v. 107, n. 11, p. 4250-6, 2006.

55. RADICH, J. P. The use of PCR technology for detecting minimal residual disease in patients with leukemia. Rev Immunogenet, v. 1, n. 2, p. 265-78, 1999.

56. RADICH, J. P. The detection and significance of minimal residual disease in chronic myeloid leukemia. Medicina (B. Aires), v. 2, p. 66-70, 2000.

57. RADICH, J. P. et al. Gene expression changes associated with progression and response in chronic myeloid leukemia. PNAS, v. 103, n. 8, p. 2794-9, 2006.

58. RADICH, J. P. et al. Polymerase chain reaction detection of the BCR-ABL fusion transcript after allogeneic marrow transplantation for chronic myeloid leukemia: results and implications in 346 patients. Blood, v. 85, n. 9, p. 2632-8, 1995.

59. RADICH, J. P. et al. The significance of bcr-abl molecular detection in chronic myeloid leukemia patients "late" 18 months or more after transplantation. Blood, v. 98, n. 6, p. 1701-7, 2001.

60. ROSAS-CABRAL, A. et al. Analysis of Bcr-abl type transcript and its relationship with platelet count in Mexican patients with chronic myeloid leukemia. Gac Med Mex, v. 139, p. 553-9, 2003.

61. ROSS, D. M. et al. Limited clinical value of regular bone marrow cytogenetic analysis in imatinib-treated chronic phase CML patients monitored by RQ-PCR for BCRABL. Leukemia, n. 4, p. 664-70, 2006.
62. ROSTI, G. et al. Molecular response to imatinib in late chronic-phase chronic myeloid leukemia. Blood, v. 103, n. 6, p. 2284-90, 2004.

63. SAWYERS, C. L. Chronic myeloid leukemia. N Engl J Med, v. 340, n. 17, p. 1330-40, 1999.

64. SCHOCK, C. et al. Comparison of chromossome banding analysis, interphase - and hypermetaphase - FISH, qualitative and quantitative PCR for diagnosis and for follow-up in chronic myeloid leukemia: a study on 350 cases. Leukemia, v. 16, n. 1, p. 53-9, 2002.

65. SHEPHERD, P. et al. Analysis of molecular breakpoint and m-RNA transcripts in a prospective randomized trial of interferon in chronic myeloid leukaemia: no correlation with clinical features, cytogenetic response, duration of chronic phase, or survival. Br J Haematol, v. 89, p. 546-54, 1995.

66. SILLABER, C. et al. Chronic myeloid leukemia: pathophysiology, diagnostic parameters, and current treatment conceps. Wien klin wochenschr, v. 115, n. 13-4, p. 485-504, 2003.

67. STROMSKAYA, T. P. et al. Role of p-glycoprotein in evolution of populations of chronic myeloid leukemia cells treated with imatinib. Biochemistry (Mosc), v. 73, n. 1, p. 29-37, 2008.

68. UDOMSAKDI-AUEWARAKUL, C. et al. Detection of molecular variants of BCR-ABL gene in bone marrow and blood of patients with chronic myeloid leukemia by reverse-transcriptase polymerase chain reaction (RTPCR). J Med Assoc Thai, v. 83, p. 928-35, 2000.

69. VELDEN, V. H. J. et al. Detection of minimal residual disease in hematologic malignancies by real-time quantitative PCR: principles, approaches, and laboratory aspects. Leukemia, v. 17, p. 1013-34, 2003.

70. VENDRAME-GOLONI, C. Chromossomal alterations and frequency of the $\mathrm{BCR} / \mathrm{ABL}$ gene rearrangement at diagnosis of chronic myeloid leukemia, treatment with imatinib mesylate followed by bone marrow. Rev Bras Hematol Hemoter, v. 28, n. 1, p. 79-80, 2006.

71. VENDRAME-GOLONI, C. et al. Frequency of the BCR/ABL rearrangements and associated alterations detected by FISH during monitoring of patients taking imatinib mesylate in isolation. Rev Bras Hematol Hemoter, v. 28, n. 2, p. 115-9, 2006.

72. WANG, Y. L. etal. Chronic myelogenous leukemia: laboratory diagnosis and monitoring. Genes Chromosomes Cancer, v. 32, n. 2, p. 97-111, 2001.

73. WEISBERG, E.; MANLEY, P.; GRIFFIN, J. D. AMN107 (nilotinib): a novel and selective inhibitor of BCR-ABL. Br J Cancer, v. 94, n. 12, p. 1765-9, 2006.

74. YIN, J. A. L. Minimal residual disease in acute myeloid leukaemia. Pract Res Clin Hematol, v. 15, n. 1, p. 119-35, 2002. 